\title{
Retraction Note: Application of remote sensing image classification based on adaptive Gaussian mixture model in analysis of mountain environment features
}

$\operatorname{Nan} \mathrm{Xu}^{1}$

Published online: 6 December 2021

(c) Saudi Society for Geosciences 2021

Retraction Note: Arabian Journal of Geosciences (2021) 14: 1486 https://doi.org/10.1007/s12517-021-07899-2

The Editor-in-Chief and the Publisher have retracted this article because the content of this article is nonsensical. The peer review process was not carried out in accordance with the Publisher's peer review policy. The author has not responded to correspondence regarding this retraction.

The original article can be found online at https://doi.org/10.1007/ s12517-021-07899-2.

Nan Xu

xunannan999@126.com

$1 \quad$ BIM and Computing Technology Research Center, Shenyang

Jianzhu University, Shenyang 110168, Liaoning, China 